KENOSIS : JURNAL KAJIAN TEOLOGI

ISSN 2460-6901(Print), 2656-4483 (Online)

https://e-journal.iaknambon.ac.id/index.php/KNS

DOI: $10.37196 /$ kenosis.v7i2.329

\title{
PENDIDIKAN KRISTEN DI KERESIDENAN TIMOR PADA MASA NEDERLANDSCH ZENDELING GENOOTSCHAP: Suatu Kajian Historis
}

\section{Fransisco de Kr. A. Jacob}

\author{
Timor Indikator \\ Jln. Murbey No 10, Oeba - Kota Kupang \\ dekristo29@gmail.com
}

\begin{abstract}
This article aims to examine and analyze how Christian education was carried out in the Timor residency during the time of the Nederlansch Zendeling Genootschap. Based on the results of the discussion, it is clear that education is a key element in the pattern of NZG evangelism. Therefore, education could never be separated from evangelism. Instead, the final destination of education is the expansion of the gospel message. The seeds of the gospel were introduced to local people through education. In its journey, the education during the NZG continued to experience ups and downs. There are problems caused by internal factors, but some are caused by external conditions. Even so, the NZG consistently continues to pay attention to the running of education services. The Christian education that has been carried out by the NZG brought a big impact on the social life of the people in the Residency of Timor.
\end{abstract}

Keywords: Education, NZG, Resident of Timor

\begin{abstract}
Abstrak
Artikel ini bertujuan untuk mengkaji dan menganalisis bagaimana jalannya pendidikan Kristen di Keresidenan Timor pada masa Nederlansch Zendeling Genootschap. Berdasarkan hasil pembahasan, nyatalah bahwa pendidikan menjadi elemen kunci dalam pola pekabaran Injil NZG. Karena itu, pendidikan tidak akan pernah bisa dilepaskan dari pekabaran Injil. Malahan, muara dari pendidikan adalah perluasan pekabaran Injil. Sebab, melalui pendidikan, benih-benih Injil mulai diperkenalkan kepada orang-orang lokal. Dalam perjalanannya, dunia pendidikan pada masa NZG terus mengalami pasang surut. Ada persoalan-persoalan yang disebabkan oleh faktor-faktor internal, namun ada juga yang disebabkan oleh kondisi eksternal. Walau begitu, NZG secara konsisten terus memberikan perhatian terhadap jalannya pelayanan pendidikan. Pendidikan Kristen yang dijalankan oleh NZG pada
\end{abstract}


akhirnya membawa dampak besar terhadap kehidupan sosial masyarakat di Keresidenan Timor.

Kata kunci: Pendidikan, NZG, Keresidenan Timor

\section{PENDAHULUAN}

Apabila kita mempelajari sejarah penyebaran Agama Kristen di dunia secara umum, dan Indonesia secara khusus, maka akan terlihat bahwa pekabaran Injil selalu berhubungan erat dengan pelayanan pendidikan. Bahkan dapat dikatakan bahwa pendidikan adalah salah satu instrumen yang digunakan para misionaris untuk menghubungkan orang-orang non Kristen dengan Injil. Dalam konteks Indonesia, hampir semua lembaga misi yang bekerja selalu memberikan perhatian terhadap pelayanan pendidikan di wilayah kerja mereka masing-masing. Di Sumatra Utara misalnya, Rheinische Missiongesellschaft (RMG) secara konsisten menunjukkan komitmennya terhadap kemajuan pendidikan. Hal yang sama juga diperlihatkan $D e$ Gereformeerde Zendings Bond (GZB) di tanah Toraja. Fakta-fakta historis ini sekali lagi menegaskan betapa terkait dan terjalinnya pelayanan pendidikan dengan pekerjaan pekabaran Injil. Pola yang sama juga dilakukan oleh Nederlandsch Zendeling Genootschap (NZG) ketika bekerja di Keresidenan Timor. ${ }^{1}$ Sebagai lembaga misi, NZG memberikan perhatian penuh terhadap pelayanan pendidikan di wilayah ini. Oleh karena itu, bagi NZG pelayanan pendidikan dan pekabaran Injil merupakan dua hal yang tidak dapat dipisahkan. Bahkan dalam pola kerjanya, NZG sering kali terlebih dahulu mendirikan sekolah ketimbang membentuk Jemaat.

Sekarang pertanyaan-pertanyaan yang muncul adalah: bagaimanakah kondisi pendidikan di Keresidenan Timor pada masa NZG berlangsung? Materi-materi apa saja yang diajarkan? Seperti apa peran para guru? Apa dampak pendidikan bagi masyarakat secara luas? Terhadap pertanyaan-pertanyaan di tersebut belum terdapat suatu kajian yang memadai. Jikalau pun ada, maka kajian yang diberikan sangatlah kurang komprehensif. Frederiek Djara Wellem misalnya, hanya mengkaji pendidikan di Keresidenan Timor pada masa NZG secara kronologis. Ia hanya secara deskriptif 
menginformasikan perkembangan pendidikan secara kronologis. Misalnya, bahwa pada tahun-tahun tertentu jumlah sekolah bertambah dari sekian hingga sekian dan pada periode-periode tertentu jumlah murid berkurang dari sekian hingga sekian. ${ }^{2}$

Berangkat dari fakta di atas, maka pengkajian mengenai konteks pendidikan Kristen di Keresidenan Timor pada masa NZG merupakan suatu keniscayaan. Dengan demikian, tujuan utama artikel ini adalah untuk mengkaji tentang kondisi pendidikan Kristen di Keresidenan Timor pada masa NZG (sesuatu yang hingga saat ini hampirhampir tidak dilakukan). Artikel ini juga berfungsi sebagai suatu sumber historis bagi siapapun yang ingin mengetahui tentang pendidikan Kristen di Keresidenan Timor. Adapun artikel ini terdiri dari enam bagian. Bagian pertama membahas dasar dan tujuan Pendidikan Kristen. Bagian kedua membahas pengorganisasian sekolah. Bagian ketiga membahas materi pendidikan. Bagian keempat mengenai dampak pendidikan bagi masyarakat, dan bagian terakhir membahas tantangan dunia pendidikan.

\section{METODE PENELITIAN}

Metode penelitian yang digunakan dalam artikel ini adalah historiografi atau yang biasa disebut metode penelitian sejarah dan tergolong ke dalam penelitian kualitatif. Historiografi adalah metode yang digunakan untuk menguji dan menganalisis catatan peristiwa masa lalu yang kemudian dikonstruksi secara kritis dan imajinatif dengan memperhatikan secara ketat bukti-bukti serta rujukan-rujukan otentik yang ada.

Penting untuk dicatat, oleh karena artikel yang mengulas tentang kondisi pendidikan Kristen di Keresidenan Timor pada masa NZG hampir-hampir tidak dapat ditemukan, maka saya kemudian beralih kepada sumber-sumber primer yang terbit sekitar 100 hingga 190 tahun yang lalu, seperti laporan-laporan lembaga misi, suratsurat para misionaris, ataupun surat-surat dari pemerintah Hindia-Belanda. Penggunaan literatur-literatur ini - meski terkadang dianggap sudah usang - sangat bermanfaat, sebab dengannya kita mendapat gambaran otentik kondisi pendidikan pada mas NZG 


\section{HASIL DAN PEMBAHASAN}

\section{Dasar dan Tujuan Pendidikan}

Pendidikan merupakan elemen kunci dalam pelayanan NZG, baik di Keresidenan Timor maupun di tempat-tempat lainnya di mana ia bekerja. Bagi NZG, pendidikan merupakan jembatan yang menghubungkan antara kekristenan dan masyarakat lokal non-Kristen. Oleh karena itu, NZG tidak memisahkan antara pekabaran Injil dan pendidikan, keduanya adalah satu adanya. Pekabaran Injil tidak mungkin dilakukan tanpa pendidikan dan pendidikan dilakukan dengan tujuan agar Injil dapat diberitakan. Dalam laporan NZG tahun 1825 disebutkan demikian: "kami menilai bahwa tidak ada cara yang lebih baik untuk menyebarkan kekristenan selain dari pada pendidikan di sekolah". Hal yang sama juga diungkapkan oleh Reint Le Bruijn - misionaris NZG yang pertama di Keresidenan Timor - dalam suratnya tertanggal 27 Oktober 1825. Ia menyebut demikian: "pendidikan di sekolah merupakan cara pertama dan terpenting untuk memperluas doktrin kekristenan". Dengan demikian, jelaslah bahwa dasar dan tujuan dari pendidikan NZG adalah kekristenan. ${ }^{3}$

Menarik untuk dicatat, sekalipun tujuan dari pendidikan NZG adalah perpindahan orang-orang lokal kepada Kekristenan, namun NZG tidak menjalankannya secara paksa. NZG ingin agar perpindahan ke dalam kekristenan dilakukan dengan motivasi yang murni, yakni karena percaya bahwa Yesus Kristus adalah Tuhan dan Juru Selamat. Itulah sebabnya pada sejumlah sekolah terdapat anakanak yang menganut kepercayaan tradisional, $\mathrm{Kong} \mathrm{Hu}-\mathrm{Cu}$, dan $\mathrm{Hindu}$, yang tetap memeluk kepercayaan mereka setelah menempuh pendidikan di sekolah NZG. Dalam laporan Umum Sekolah-sekolah di Hindia-Belanda tahun 1855, disebutkan bahwa jumlah murid pada Sekolah Melayu di Kupang adalah sebanyak 101 orang. Tiga puluh di antaranya beragama Kong $\mathrm{Hu}-\mathrm{Cu}$ dan dua belas beragama Hindu. Dalam laporan yang sama juga disebutkan bahwa pada sekolah di Oelio terdapat sembilan murid yang memeluk agama Hindu. ${ }^{4}$ Hal ini menunjukkan bahwa penyebaran kekristenan yang dilakukan NZG melalui sekolah tidak ditempuh dengan cara paksaan. $^{5}$ 
Perhatian NZG yang besar terhadap pendidikan terlihat jelas dari keseriusannya mengurusi persoalan-persoalan pendidikan. Salah satu gebrakan yang dibuat NZG adalah dengan mendirikan Lembaga Bantuan Pekabaran Injil. Lembaga ini didirikan pada tahun 1824 di Kupang oleh misionaris NZG bernama Reint Le Bruijn bekerja sama dengan Residen (Jacobus Arnoldus Haazart) dan Sekretaris Residen Kupang (J. M. Tielman). Tugas utama dari lembaga ini adalah mendukung pekerjaan NZG, khususnya dalam dunia pendidikan. Lembaga ini berfungsi untuk menyediakan tenaga pengajar, pengadaan bahan bacaan, pencarian donatur, mendirikan gedung sekolah, dan lain-lain yang berkaitan dengan pendidikan. Pada waktu-waktu selanjutnya komitmen dan konsistensi NZG untuk memajukan pendidikan terus terlihat. Hal ini dibuktikan dengan banyaknya jumlah sekolah yang didirikan dari tahun ke tahun. Dalam konteks Timor Barat misalnya, NZG berhasil mendirikan lima sekolah dalam waktu lima tahun sejak ia mulai bekerja (1820-1825). Kemudian pada tahun 1836 jumlah ini meningkat menjadi tujuh sekolah dan pada tahun 1850-an tercatat terdapat delapan ${ }^{6}$ sekolah yang beroperasi di seluruh Timor Barat. $^{7}$

Dalam menjalankan pelayanan pendidikan, NZG berusaha untuk menembus berbagai sekat-sekat sosial yang ada dalam masyarakat. Karenanya, NZG tidak hanya membuka sekolah kepada anak-anak bangsawan atau anak-anak dari kalangan orang merdeka, melainkan juga kepada para budak. Sekolah ini - kendatipun hanya berlangsung selama empat tahun (1824-1828) - namun telah banyak melahirkan tamatan-tamatan yang cerdas, yang dikemudian hari memainkan peran penting bagi pertumbuhan kekristenan di Kupang. Tantangan utama yang dihadapi NZG berkaitan dengan pendidikan budak adalah resistensi dari para pemilik budak. Para majikan ingin agar budak-budak yang mereka miliki tetap berada dalam kondisi tak terdidik sehingga akan jauh lebih mudah diperalat. Selain itu, kemungkinan bahwa seorang budak mendapatkan kebebasannya setelah bersekolah dan menjadi Kristen jauh lebih besar ketimbang budak yang tak bersekolah. Itulah sebabnya para majikan berusaha untuk menghalangi mereka mendapatkan pendidikan di sekolah. ${ }^{8}$ 


\section{Pengorganisasian}

Dalam relasinya dengan pemerintah Hindia-Belanda, NZG berkedudukan sebagai salah satu lembaga atau pihak swasta yang diizinkan oleh pemerintah untuk mengurusi ihwal-ihwal pekabaran Injil, termasuk di dalamnya pelayanan pendidikan. Karena itu, pengorganisasian sekolah tidak sepenuhnya dilakukan sendiri oleh NZG, melainkan dalam koordinasi dan kerja sama dengan Pemerintah Hindia-Belanda. Itulah sebabnya, pemerintah Hindia-Belanda rutin mengirimkan inspektur untuk memeriksa kondisi sekolah-sekolah yang ada di bawah pengawasan NZG. ${ }^{9}$ Selain itu, penting untuk dicatat bahwa kebijakan NZG mengenai pendidikan sangat bergantung terhadap kebijakan pemerintah Hindia-Belanda. Misalnya, pada tahun 1825 NZG harus merelakan dua sekolahnya di Kupang diambil alih menjadi sekolah negeri. Contoh lain adalah bahwa NZG harus mengikuti keputusan pemerintah HindiaBelanda yang mengatur tentang jumlah gaji para guru. ${ }^{10}$

Apabila merujuk pada laporan-laporan pekerjaan NZG di pulau Timor sejak 1820 hingga 1830-an, maka dapat dilihat bahwa pengorganisasian sekolah berjalan dengan sangat sederhana. Setiap sekolah hanya memiliki satu kelas dan satu orang guru. Itu artinya, pada tahun-tahun tersebut belum terjadi pembagian murid berdasarkan kelas. Barulah pada tahun 1837 NZG melaporkan adanya kategorisasi siswa berdasarkan kelas. Kategorisasi ini pun tidak berlaku untuk semua sekolah NZG, melainkan hanya terhadap sekolah dengan jumlah murid yang banyak seperti di Kupang dan Babau. Dalam laporan ini disebutkan bahwa siswa dibagi ke dalam tiga kelas, yaitu kelas satu (kelas atas), kelas dua (kelas menengah), dan kelas tiga (kelas dasar). Masing-masing kelas menggambarkan tingkat kemampuan seorang siswa. Setiap kelas terbagi lagi menjadi dua kelompok berdasarkan jenis kelamin. Dengan demikian pendidikan antara anak perempuan dan laki-laki berlangsung secara terpisah. Selanjutnya, pada setiap kelas terdapat seorang murid yang diangkat menjadi koordinator atau ketua kelas. Di samping itu, seorang ketua kelas juga biasanya ditugaskan untuk membantu sang guru untuk membimbing serta mengajar rekanrekannya yang masih belum memahami materi pelajaran dengan baik. Itulah mengapa seorang ketua kelas biasanya selalu merupakan murid yang tercerdas. ${ }^{11}$ Ketika bekerja di Sabu, pengorganisasian sekolah juga dilakukan kurang lebih dengan cara yang 
sama seperti di Timor. Pada jemaat-jemaat kecil, murid-murid diajari dalam satu kelas secara bersamaan, sedangkan pada Jemaat besar seperti Seba, murid-murid dibagi ke dalam tiga kelas. ${ }^{12}$

Di Rote, tidak terdapat laporan yang menunjukkan bahwa pada masa NZG pengorganisasian pendidikan di wilayah ini juga terbagi dalam beberapa kelas sebagaimana yang terjadi di Timor dan Sabu. Hal ini sangat disayangkan sebab jumlah murid pada setiap sekolah di Rote - khususnya setelah tahun 1838 - jauh melebihi jumlah murid yang ada di Kupang ataupun Sabu. Sebagai contoh, Heijmering membuka sekolah di Termanu pada tahun 1838 dengan jumlah murid sebanyak 158 orang. Ketika pada tahun yang sama membuka sekolah di Ringau, ia juga memulainya dengan kurang lebih 303 siswa. $^{13}$ Dua tahun kemudian (1840) jumlah ini terus bertambah dan total siswa di seluruh Rote mencapai 1650 orang. Dengan jumlah murid sebanyak ini dan tanpa pembagian kelas serta jumlah guru yang memadai, maka proses belajar-mengajar tidak berjalan secara efisien. Bahkan Hartig, sendiri kesusahan untuk mengajari semua murid yang ada. Karena itu, ia membuat kebijakan untuk membentuk kelompok-kelompok belajar yang terdiri dari 2-4 siswa. Masing-masing kelompok diberikan satu buku pelajaran dan diharapkan mereka dapat belajar membaca, menulis, dll., secara mandiri. ${ }^{14}$

Penting untuk dicatat bahwa meski secara organisatoris NZG bertanggung jawab terhadap pelaksanaan pendidikan, namun ada saat-saat tertentu di mana pengorganisasian dan pengoperasiannya dilakukan sepenuhnya oleh majelis jemaatmajelis jemaat lokal yang ada. Majelis-majelis jemaat ini memainkan peran untuk menjaga agar pelayanan pendidikan tetap berlangsung. Hal ini misalnya terjadi di Sabu pada tahun 1884 hingga 1888 ketika masa peralihan antara misionaris J. K. Wijnggarden dengan Bieger. Kondisi yang sama juga pernah terjadi di Rote pada tahun 1840-an hingga 1850-an ketika NZG tidak lagi mengirim misionarisnya ke tempat ini. Pada waktu itu, raja-raja di Rote menanggung penuh segala biaya yang berkaitan dengan pelayanan pendidikan, termasuk di dalamnya membayar gaji para guru. ${ }^{15}$ 


\section{Materi Pendidikan}

Sebagaimana telah disebutkan sebelumnya, tujuan dari pendidikan adalah perpindahan orang-orang non-Kristen menjadi Kristen. Oleh karena itu, materi-materi pendidikan dirancang untuk mencapai tujuan tersebut. Misalnya, untuk materi membaca dan pengenalan akan alfabet, para murid berlatih menggunakan Alkitab sebagai sumber bacaannya. Begitu pula materi menulis, para siswa diminta untuk menulis atau menyalin kembali bagian-bagian dalam Alkitab. Hal yang sama juga berlaku bagi materi mata pelajaran bernyanyi. Sumber-sumbernya terambil dari berbagai nyanyian rohani dan mazmur. Dengan demikian, proses penanaman nilainilai kekristenan secara otomatis terjadi ketika proses belajar-mengajar berlangsung.

Dalam laporannya, P. J. Veth menyebutkan bahwa pada tahun 1824 materi pendidikan yang diajarkan di sekolah-sekolah NZG meliputi empat hal, yakni membaca, menulis, bernyanyi dan pokok-pokok dasar iman Kristen. ${ }^{16}$ Selanjutnya, dalam laporan Umum Sekolah-sekolah di Hindia Belanda tahun 1832, disebutkan terdapat materi pendidikan tambahan, yakni ilmu berhitung (aritmatika). Dengan demikian, hingga tahun 1832 setidaknya terdapat lima materi yang diajarkan di sekolah. Selanjutnya, dua tahun kemudian (1834), Heijmering melaporkan adanya materi pelajaran tambahan yang diperuntukkan untuk anak-anak perempuan. Materi ini adalah keterampilan yang mencakup keterampilan memasak dan keterampilan menjahit. ${ }^{17}$

Bobot materi yang diberikan kepada setiap murid berbeda-beda, tergantung dari kemampuan sang murid tersebut. Dalam hal menulis misalnya, bobot materi yang diberikan kepada murid kelas dasar (kelas tiga) berbeda dengan murid kelas atas (kelas satu). Murid kelas dasar hanya diminta untuk menulis sejumlah kata atau pun mengenali huruf-huruf alfabet, sedangkan murid-murid kelas atas diminta untuk menulis surat kepada guru mereka setiap dua minggu. Surat-surat ini berisi refleksi dari para murid mengenai pengenalan mereka akan kekristenan ataupun Yesus Kristus. $^{18}$

Semua mata pelajaran disampaikan dalam bahasa melayu rendah atau tinggi, bergantung dari kemampuan para murid. Walau begitu, bahasa melayu tinggi biasanya hanya digunakan pada kelas satu. Selain itu, khusus untuk sekolah Belanda di 
Kupang, mata pelajaran di sampaikan dalam bahasa Belanda. Menarik untuk dicatat bahwa terdapat perbedaan kebijakan mengenai penggunaan bahasa di sekolah ketika NZG bekerja di Timor - Rote dengan di Sabu. Ketika bekerja di Timor dan Rote (1820-1860), NZG menekankan pada pentingnya penggunaan bahasa melayu. NZG bahkan menganjurkan agar murid-murid yang tidak bisa berbahasa melayu diberikan ganjaran. Bagi NZG bahasa melayu jauh lebih "bergengsi” dibandingkan dengan bahasa lokal. Karena itu, segala hal yang berkaitan dengan pekabaran Injil, termasuk di dalamnya pendidikan, harus menggunakan bahasa Melayu. ${ }^{19}$ Sebaliknya di Sabu, NZG malah menekankan bahwa materi pelajaran haruslah disampaikan dalam bahasa Sabu. Memang dalam praktiknya bahasa melayu masih menjadi bahasa pengantar. Akan tetapi, penekanan NZG pada penggunaan bahasa Sabu sebagai bahasa pengantar di sekolah - dan bahkan bahasa pengantar dalam setiap khotbah dan pengajaran keagamaan - menunjukkan adanya perubahan kebijakan NZG. Bahkan NZG mulai menerjemahkan sejumlah nyanyian dan bagian Alkitab ke dalam bahasa Sabu sesuatu yang tidak pernah dilakukan NZG ketika bekerja di Rote dan Timor. ${ }^{20}$

Pada tahun 1850-an, ketika Pemerintah Hindia-Belanda mulai mengambil alih seluruh sekolah-sekolah NZG di Timor dan Rote, dilakukanlah perubahan materi pendidikan sekolah. Perubahan tersebut adalah sebagai berikut: Mata pelajaran untuk siswa kelas tiga adalah membaca, menulis, penghafalan, ilmu hitung, dan bernyanyi. Mata pelajaran untuk kelas dua adalah dasar-dasar geografi, geografi nusantara, linguistik, membaca II, menulis II, aritmatika II, dan nyanyian. Mata pelajaran untuk kelas satu adalah membaca III, menulis III, geografi III, linguistik III, dan sejarah umum III. ${ }^{21}$

\section{Guru}

Guru memiliki peran dan fungsi yang sangat penting. Pertama, guru merupakan ujung tombak dari pelayanan pendidikan. Dialah yang bertanggung jawab penuh merawat, mengoordinasi, dan mencerdaskan murid-murid. Ia juga bertanggung jawab terhadap peningkatan jumlah siswa pada sebuah sekolah. Karenanya, seorang guru tidak bisa hanya bersikap pasif dan menunggu anak-anak yang berinisiatif datang ke sekolah, melainkan dialah yang harus mencari mereka satu per satu. Sebagai contoh, guru di Oesao hanya memiliki dua belas murid ketika sekolah pertama kali 
dibuka pada November 1836. Kemudian pada Januari 1837 ia mengunjungi rumahrumah penduduk untuk menemukan anak-anak yang masih dapat bersekolah. Hasilnya sangat mengagumkan, ia menemukan kurang lebih seratus anak-anak yang dapat bersekolah. Enam puluh di antaranya bahkan telah terdaftar sebagai murid pada Maret 1837. ${ }^{22}$ Selain bertanggung jawab untuk mencerdaskan serta meningkatkan jumlah murid, seorang guru juga bertanggung jawab terhadap peningkatan kualitas hidup muridnya, baik dari segi etika dan moral. Karenanya, seorang guru tidak hanya harus cerdas dan memiliki kemampuan manajerial yang mumpuni, melainkan juga memiliki karakter yang baik. Dalam banyak kasus, pertumbuhan suatu sekolah sangat ditentukan oleh karakter dari sang guru. Di Babau misalnya, pelayanan pendidikan menunjukkan pertumbuhan positif sebab sang guru dan istrinya memberikan teladan yang sangat baik kepada masyarakat sekitar. Sebaliknya, di Rote, Terlinden pernah memecat semua guru yang ada pada tahun 1829 karena sikap dan perilaku mereka yang buruk. Akibatnya, pelayanan pendidikan di sana harus terhenti selama beberapa tahun. $^{23}$

Peran dan fungsi kedua dari guru - yang tentu saja tidak kalah penting dari yang pertama - adalah sebagai penanggung jawab jemaat dan pekabar Injil. Hampir sama seperti seorang misionaris atau pendeta, guru juga dilimpahi dengan tugas-tugas pelayanan gerejawi - minus pelayanan sakramen dan pemberkatan nikah - seperti memimpin kebaktian, mengajar katekisasi, mengadakan percakapan pastoral, melakukan perkunjungan, dan memberitakan Injil kepada orang-orang non-Kristen. Bahkan secara jujur harus diakui bahwa para gurulah yang setiap harinya berhadapan dengan pergumulan jemaat dan bukannya para misionaris. Pada masa pelayanan Le Bruijn (1820-1829) misalnya, ia hanya beberapa kali mengunjungi pulau Rote. Selebihnya orang-orang Kristen yang ada di sana dibiarkan hidup sendiri di bawah bimbingan para guru. Hal yang sama juga terjadi di Sabu ketika terjadi kekosongan misionaris pada 1884 hingga 1888 . Hal ini menunjukkan beta vitalnya peran seorang guru dalam pekerjaan pekabaran Injil. Memang harus diakui bahwa dalam banyak hal, para guru tidak memiliki wawasan dan pengetahuan teologi yang cukup bila dibandingkan para misionaris. Akan tetapi, bagaimanapun juga mereka telah menjadi salah satu "tiang penyangga" yang menjaga agar kekristenan tetap berdiri kokoh. ${ }^{24}$ 
Selanjutnya, guru juga memiliki tingkatan jabatan. Dalam laporan NZG tahun 1837 disebutkan bahwa jabatan tenaga pengajar terbagi menjadi dua. Pertama adalah onderwijzer atau bisa disebut juga sebagai guru kepala dan kedua adalah hulponderwijzer atau yang biasa disebut sebagai guru bantu. Seorang onderwijzer biasanya juga menjabat sebagai kepala sekolah. Tampaknya klasifikasi guru berdasarkan jabatan ini baru muncul ketika sekolah-sekolah NZG semakin berkembang dan mapan. Pasalnya, klasifikasi ini tidak ditemukan dalam laporanlaporan selama sepuluh tahun pertama NZG bekerja di Keresidenan Timor. Kemudian, pada tahun 1855, pendeta Buddingh yang melakukan inspeksi ke Kupang mengusulkan agar guru-guru yang ada di Keresidenan Timor dikelompokkan dalam tiga kategori, yakni guru kelas tiga, guru kelas dua, dan guru kelas satu. ${ }^{25}$ Adapun mengenai pembayaran gaji para guru yang bekerja di Timor dan Rote, kita mendapat beberapa informasi demikian. Pertama, pada tahun 1819 pemerintah Hindia-Belanda mengeluarkan kebijakan untuk membayar penuh gaji setiap guru yang dipekerjakan NZG di Keresidenan Timor. Kebijakan ini berlangsung hingga tahun 1831. Selanjutnya, sejak tahun 1834 hingga 1837 subsidi pemerintah tetap diberikan tetapi dalam bentuk parsial. Dalam periode ini gaji yang diterima adalah sebesar enam belas gulden $(16 f)$. Enam gulden dibayarkan pemerintah sedangkan sisanya dibayar NZG. Besaran ini kemudian mengalami perubahan sejak tahun 1837. Dalam laporan NZG disebutkan bahwa gaji guru adalah sebesar dua puluh gulden $(20 f)$, sedangkan gaji guru bantu adalah delapan gulden $(8 f)$. Semua pembiayaan ini berasal dari kas NZG, kecuali guru sekolah negeri di Kupang yang digaji dari kas pemerintah HindiaBelanda. Pada waktu itu guru di Kupang menerima gaji sebesar tiga puluh gulden (30 f) setiap bulan. Kemudian, pada tahun 1855, setelah melakukan kunjungan ke Keresidenan Timor, Buddingh mengusulkan agar seluruh gaji guru ditanggung penuh oleh pemerintah Hindia-Belanda dengan besaran sebagai berikut: guru kelas satu sebesar 25 gulden (25f), guru kelas dua sebesar 20 gulden $(20 f)$, dan guru kelas tiga sebesar 15 gulden $(15 f) .{ }^{26}$

Penting untuk dicatat bahwa tidak selamanya pembayaran gaji para guru berjalan dengan lancar. Sering kali mereka tidak menerima gaji selama berbulan-bulan atau bahkan bertahun-tahun. Di Rote misalnya, terdapat empat orang guru yang mengajar tanpa digaji selama empat tahun. Mereka ini adalah Zadrak Molle di Ba'a, 
Jacob Klau di Lole, Tobias Mae di Bilba, dan Pieter Talahatu di Ringo. Barulah pada tahun 1856 Pemerintah Hindia-Belanda memberikan kepada mereka gratifikasi, masing-masing sebesar 250 gulden $(250 f) .{ }^{27}$ Apabila para guru belum menerima gaji, maka biasanya anggota jemaat memberikan kepada mereka subsidi dalam bentuk natura hasil bumi seperti padi, jagung, ternak kecil, dan lain-lain. Ketika NZG bekerja di Sabu sejak tahun 1872-1903, metode pembayaran yang sama juga sering dilakukan. Para guru menerima bahan makanan atau hasil bumi sebagai ganti atas gaji mereka. Selain itu, mereka juga sering menerima tunjangan pada hari natal sebesar 10 hingga 25 gulden. ${ }^{28}$ Pada tahun 1885 terdapat keputusan mengenai pembayaran gaji para guru di Sabu yang berbunyi demikian:

Seтиa hadiah dari panen tahunan yang terdiri dari kacang, jagung, dan gula, yang sampai saat ini telah dijual untuk kas jemaat, dapat disimpan oleh para guru untuk keperluan mereka sendiri. Ini sebagai tambahan untuk gaji mereka yang rendah. ${ }^{29}$

\section{Tantangan Pendidikan}

Pendidikan yang dijalankan NZG sudah tentu tidak bebas dari tantangan dan persoalan. Dalam berbagai laporannya, NZG selalu menyebutkan berbagai hal yang mereka hadapi di Keresidenan Timor berkaitan dengan pelayanan pendidikan. Dari hasil analisis saya, terdapat sekurang-kurangnya tiga hal yang menjadi tantangan utama NZG dalam menjalankan pelayanan pendidikan di Keresidenan Timor.

Pertama, kekurangan tenaga pengajar. Kekurangan tenaga pengajar selalu menjadi salah satu persoalan yang dihadapi NZG sejak ia mulai bekerja hingga penarikan dirinya. Hal ini disebabkan oleh kecilnya sumber daya keuangan NZG. Dalam berbagai surat mereka, para misionaris NZG berulang kali mengeluhkan kondisi ini. Mereka mengatakan bahwa seandainya NZG menerima sumbangan yang lebih besar, maka tentu itu dapat mendongkrak pertumbuhan pendidikan dengan cara mempekerjakan banyak guru. Dalam laporan NZG tahun 1837, Heijmering menulis demikian kepada jemaat-jemaat pendonor NZG di Belanda:

Saudara dan saudari! Kami akan selalu berusaha mengerjakan pekerjaan Tuhan di sini dengan tekun dan ceria. Tetapi, apakah anda juga dapat mendukung kelemahan kami, tidak hanya melalui doa-doa yang tentu saja sangat kami hargai, namun juga melalui kontribusi yang nyata.... Kalau begitu jangan biarkan saya yang mau bekerja terhambat oleh berhematmu. Tidak pernah ada begitu banyak siswa di Timor 
seperti saat ini, tetapi kebutuhan sekolah kami juga tidak perrnah sebesar seperti sekarang ini. ${ }^{30}$

Keadaan ini semakin diperparah dengan kenyataan bahwa tidak semua guruguru yang dipekerjakan NZG memiliki perilaku yang baik dan berkomitmen kuat terhadap kemajuan pendidikan. Terdapat guru-guru yang melakukan tindakan kekerasan dan pelecehan seksual kepada murid-murid. Hal ini menyebabkan ketakutan dari orang tua untuk menyekolahkan anak-anak mereka. ${ }^{31}$

Kedua, halangan dari orang tua murid. Upaya NZG untuk mendidik anak-anak tampaknya tidak selalu didukung oleh para orang tua. Sebaliknya, para orang tua sering kali menghalangi dan melarang anak-anaknya untuk mengikuti pendidikan di sekolah. Berdasarkan pembacaan saya terhadap berbagai laporan NZG, setidaknya terdapat dua faktor penyebab. Pertama karena ketakutan orang tua bahwa dengan bersekolah anak-anak mereka akan menjadi Kristen dan meninggalkan kepercayaan leluhur. Kedua, para orang tua akan kehilangan "tenaga kerja" yang seharusnya dapat membantu mereka mengurusi berbagai macam pekerjaan rumah. Di Babau misalnya, Donselaar menemukan bahwa rendahnya tingkat kehadiran anak-anak di sekolah disebabkan karena banyaknya pekerjaan rumah tangga yang harus dilakukan. Anakanak bertanggung jawab memberi makan hewan peliharaan, mengambil air di sumur (biasanya sumur terletak cukup jauh dari rumah penduduk). Mengumpulkan kayu bakar, bekerja di kebun atau ladang, dan berbagai pekerjaan lainnya. Bahkan ketika musim panen atau tanam telah tiba, maka anak-anak akan menetap di "rumah kebun" bersama dengan orang tua mereka selama lebih dari empat bulan. Sebenarnya Heijmering pernah mencoba mengatasi persoalan ini dengan membuka kelas malam supaya anak-anak dapat tetap membantu orang tua mereka pada waktu siang. Akan tetapi, kelas ini terbukti sangat tidak efektif sehingga harus ditiadakan. ${ }^{32}$

Ketiga, halangan dari elite lokal. Sebagaimana diketahui, para bangsawan memiliki pengaruh yang sangat kuat dalam wilayah yang mereka pimpin. Karena itu, keberhasilan NZG juga sering kali ditentukan oleh harmonis atau tidaknya relasi mereka dengan para elite lokal. Apabila relasi yang terbangun harmonis, maka sudah dapat dipastikan bahwa para elit ini juga akan mendukung mereka, namun apabila tidak, maka mereka akan menentang pekerjaan NZG. Di Baun misalnya, pendidikan terhadap anak-anak dari kelas biasa dan perempuan tidak dapat dilakukan sekalipun 
NZG sangat menginginkannya. Pasalnya, para bangsawan di sana hanya mengizinkan anak laki-laki bangsawan untuk bersekolah. Mereka bahkan mengancam akan menentang segala upaya NZG apabila sekolah yang didirikan juga mengizinkan anakanak dari strata sosial yang rendah serta perempuan untuk bersekolah. Hal yang sama juga ditemui Vermassen ketika melakukan kunjungan ke berbagai sekolah di Timor. Ia menemukan bahwa para bangsawan lokal akan segera menarik dukungannya, termasuk melarang anak-anak mereka pergi ke sekolah apabila anak-anak dari strata sosial yang rendah juga diperbolehkan mengikuti pendidikan. ${ }^{33}$

Sebenarnya keterikatan antara NZG dan para elite lokal juga disebabkan oleh metode pendekatan NZG yang bersifat top-down. Tidak seperti di Jawa, sasaran pertama NZG di Keresidenan Timor adalah para bangsawan lokal. NZG berharap dengan cara ini akan lebih mudah mengajak rakyat biasa untuk menjadi Kristen. Dalam praktiknya hal ini memang terjadi, yakni banyak rakyat biasa yang kemudian beralih menjadi Kristen setelah melihat pemimpinnya terlebih dahulu menjadi Kristen. Akan tetapi, pendekatan yang demikian menyebabkan NZG juga tidak dapat berbuat banyak apabila mereka ditentang oleh para bangsawan. ${ }^{34}$

\section{Dampak Pendidikan terhadap Masyarakat}

Pendidikan yang baik haruslah memberi dampak bagi masyarakat secara luas. Di Keresidenan Timor, pendidikan Kristen yang dilakukan NZG juga berdampak terhadap kondisi sosial masyarakat yang ada. Saya mencatat sejumlah dampak pendidikan sebagai berikut. Pertama, pendidikan berdampak terhadap meluasnya nilai-nilai kekristenan. Dalam laporan-laporan misionaris disebutkan bahwa para alumni sekolah-sekolah NZG biasanya kembali ke tempat asal mereka dan turut memperkenalkan nilai-nilai kekristenan ke dalam komunitas mereka yang mayoritas anggotanya masih menganut kepercayaan tradisional. Hal ini bahkan dilakukan oleh para murid yang belum dibaptis menjadi Kristen. Dengan cara seperti ini, maka meluaslah nilai-nilai kekristenan kepada masyarakat-masyarakat lokal, sekalipun mereka belum dibaptis atau mengikuti pengajaran keagamaan. Dalam suratnya tanggal 3 Agustus 1876, Teffer menyebutkan bahwa seorang bangsawan dari Pulau Raijua merupakan alumni dari sekolah berbahasa Melayu di Kupang. Ketika selesai menempuh pendidikan di Kupang ia kembali ke kampung halaman dengan status 
belum menjadi Kristen. Uniknya, ketika tiba di Raijua, dialah orang yang memperkenalkan nilai-nilai kekristenan kepada masyarakat yang ada di sana. Hal yang sama juga dilakukan oleh seorang laki-laki bernama Jonas di Amarasi. Ia adalah murid dari Le Bruijn di Sekolah Melayu Kupang dan masih berstatus sebagai penganut kepercayaan tradisional setelah menyelesaikan studinya di Kupang. Kendati demikian, ketika kembali di Amarasi, Jonaslah orang yang memperkenalkan nilainilai kekristenan kepada kerabatnya. ${ }^{35}$

Kedua, pendidikan berdampak pada perubahan dan pembaharuan kebudayaan. Melalui pendidikan, NZG tidak hanya mengajarkan orang-orang lokal cara membaca atau berhitung, melainkan juga mengubah kebiasaan dan adat istiadat mereka. Pada satu sisi perubahan membawa dampak positif, sebab dengannya orang-orang lokal mengenal kebudayaan baru yang lebih maju. Akan tetapi, pada sisi yang lain ini juga mengakibatkan tercabutnya orang-orang lokal dari kebudayaan mereka sendiri. Bahkan tidak jarang bahwa mereka yang telah bersekolah dan bersentuhan dengan kebudayaan Eropa menganggap mereka yang berbudaya lokal sebagai orang-orang yang lebih rendah derajatnya. Sebagai contoh, orang-orang yang bersekolah dan mengenal bahasa melayu atau Belanda menganggap bahasa lokal sebagai sesuatu yang lebih rendah nilainya. Terkadang mereka merasa malu untuk menggunakan bahasa lokal mereka. ${ }^{36}$

Ketiga, pendidikan berdampak terhadap berkurangnya praktik perbudakan. Sebagaimana telah saya sebutkan di atas, seorang budak yang mengikuti pendidikan dan menjadi Kristen memiliki kemungkinan yang jauh lebih besar untuk dimerdekakan ketimbang mereka yang tidak bersekolah. Sebab dengan menjadi Kristen, mereka tidak bisa lagi diperbudak. Selain itu, para majikan yang mengikuti pendidikan juga diajarkan bahwa perbudakan adalah sesuatu yang ditentang oleh Alkitab. Karena itu, mereka juga perlahan-lahan mulai membebaskan budak yang mereka punya. Dengan demikian, pendidikan secara perlahan berdampak terhadap berkurangnya praktik perbudakan. ${ }^{37}$

\section{KESIMPULAN}

Pendidikan merupakan elemen kunci dalam pelayanan NZG di Keresidenan Timor. Bagi NZG, pendidikan merupakan instrumen untuk membawa orang-orang 
non-Kristen ke dalam kekristenan. Oleh karena itu, pelayanan pendidikan tak dapat dipisahkan dengan aktivitas pekabaran Injil. Keduanya berjalan beriringan. Dalam menjalankan pendidikan, NZG selalu mengalami pasang-surut. Ada saat-saat di mana pendidikan mengalami kemajuan pesat, namun ada saat-saat juga ketika mengalami kemunduran. Kendati begitu, NZG tetap konsisten dalam upayanya untuk memajukan pendidikan. Pada akhirnya, pendidikan yang dilaksanakan NZG membawa dampak besar, tidak hanya bagi kehidupan orang-orang Kristen (gereja), melainkan juga bagi kondisi sosial masyarakat di Keresidenan Timor. Bahkan hingga masa kini "benihbenih" pendidikan yang ditabur oleh para misionaris NZG telah meluas dan telah menghasilkan banyak buah di Timor, Rote, dan Sabu.

\section{Endnotes:}

\footnotetext{
${ }^{1}$ Penting untuk dicatat bahwa masa pelayanan NZG di Keresidenan Timor terbagi menjadi dua periode. Periode pertama berlangsung dari tahun 1820-1860 dan periode yang kedua berlangsung dari tahun 1872-1903. Pada periode yang pertama wilayah pelayanan NZG mencakup Pulau Timor dan Rote, sedangkan pada periode kedua hanya mencakup Pulau Sabu.

${ }^{2}$ Frederiek Djara Wellem, Sejarah Gereja Masehi Injili Di Timor (Jakarta: Pertama Aksara, 2011), 34 72.

${ }^{3}$ Kedua kutipan di atas telah diterjemahkan oleh penulis. Nederlandsch Zendeling-Genootschap, Maanberigten Voorgelezen Op de Maandelijksche Bedestonden van Het Nederlansch ZendelingGenootschap 1827 (Rotterdam: NZG, 1827), 124.

${ }^{4}$ De Hoofd-Kommissie van Onderwijs, Algemeen Verslag van Den Staat van Het Schoolwezen in Nederlansch-Indie 1852 (Batavia: Ter Lands Drukkerij, 1853), 125-26.

5 Nederlandsch Zendeling-Genootschap, Maanberigten Voorgelezen $O p$ de Maandelijksche Bedestonden van Het Nederlansch Zendeling-Genootschap 1876 (Rotterdam: NZG, 1876), 158-59; Nederlandsch Zendeling-Genootschap, Maanberigten Voorgelezen Op de Maandelijksche Bedestonden van Het Nederlansch Zendeling-Genootschap 1877 (Rotterdam: NZG, 1877), 39.

${ }^{6}$ Sebenarnya pada tahun di antara 1841 NZG membuka lagi empat sekolah di lokasi berbeda (Oekabiti, Baun, Oepura, dan Bakunase). Sayang sekali beberapa tahun kemudian sekolah-sekolah ini ditutup lantaran ketiadaan tenaga pengajar. Lih. Nederlandsch Zendeling-Genootschap, Maanberigten Voorgelezen Op de Maandelijksche Bedestonden van Het Nederlansch Zendeling-Genootschap 1843 (Rotterdam: NZG, 1843).

${ }^{7}$ Fransico de Ch A Jacob, "Gereja Protestan Di Timor Barat Pada Masa Nederlandsch Zendeling Genootschap, 1820-1860: Suatu Kajian Mengenai Sejarah Dan Bentuknya,” Theologia in Loco 3, no. 1 (2021): 23-25.

${ }^{8}$ Zendeling-Genootschap, Maanberigten Voorgelezen $O p$ de Maandelijksche Bedestonden van Het Nederlansch Zendeling-Genootschap 1827, 118-19; Nederlandsch Zendeling-Genootschap, Maanberigten Voorgelezen Op de Maandelijksche Bedestonden van Het Nederlansch ZendelingGenootschap 1837 (Rotterdam: NZG, 1837), 185.

9 Nederlandsch Zendeling-Genootschap, Maanberigten Voorgelezen $O p$ de Maandelijksche Bedestonden van Het Nederlansch Zendeling-Genootschap 1892 (Rotterdam: NZG, 1892), 44; De Hoofd-Kommissie van Onderwijs, Algemeen Verslag van Den Staat van Het Schoolwezen in Nederlansch-Indie 1855 (Batavia: Ter Lands Drukkerij, 1856), 125.

${ }^{10}$ Zendeling-Genootschap, Maanberigten Voorgelezen Op de Maandelijksche Bedestonden van Het Nederlansch Zendeling-Genootschap 1827, 121; De Hoofd-Kommissie van Onderwijs, Algemeen Verslag van Den Staat van Het Schoolwezen in Nederlansch-Indie 1856 (Batavia: Ter Lands Drukkerij, 1857), 129-30.
} 
11 Zendeling-Genootschap, Maanberigten Voorgelezen Op de Maandelijksche Bedestonden van Het Nederlansch Zendeling-Genootschap 1837, 188.

12 Nederlandsch Zendeling-Genootschap, Maanberigten Voorgelezen Op de Maandelijksche Bedestonden van Het Nederlansch Zendeling-Genootschap 1891 (Rotterdam: NZG, 1891), 134.

${ }^{13}$ Di dua wilayah lainnya di Rote Heijmering juga membuka sekolah dengan jumlah murid yang tinggi. Di Oepao sekolah dibuka dengan 150 siswa, dan di Bilba sekolah dibuka dengan 300 siswa. Nederlandsch Zendeling-Genootschap, Maanberigten Voorgelezen Op de Maandelijksche Bedestonden van Het Nederlansch Zendeling-Genootschap 1839 (Rotterdam: NZG, 1839), 127.

14 Nederlandsch Zendeling-Genootschap, Maanberigten Voorgelezen Op de Maandelijksche Bedestonden van Het Nederlansch Zendeling-Genootschap 1841 (Rotterdam: M. Wijt \& Zonen, 1841), 158.

${ }^{15}$ P. J. Veth, Het Eiland Timor (Amsterdam: Penerbit tidak teridentifikasi, 1855), 109.

16 Veth, 106.

17 De Hoofd-Kommissie van Onderwijs, Algemeen Verslag van Den Staat van Het Schoolwezen in Nederlansch-Indie 1832 (Batavia: Ter Lands Drukkerij, 1833), 53; Nederlandsch ZendelingGenootschap, Maanberigten Voorgelezen Op de Maandelijksche Bedestonden van Het Nederlansch Zendeling-Genootschap 1836 (Rotterdam: NZG, 1836), 6.

18 Zendeling-Genootschap, Maanberigten Voorgelezen Op de Maandelijksche Bedestonden van Het Nederlansch Zendeling-Genootschap 1837, 188-90.

19 Nederlandsch Zendeling-Genootschap, Maanberigten Voorgelezen Op de Maandelijksche Bedestonden van Het Nederlansch Zendeling-Genootschap 1842 (Rotterdam: NZG, 1842), 137.

20 Nederlandsch Zendeling-Genootschap, Maanberigten Voorgelezen Op de Maandelijksche Bedestonden van Het Nederlansch Zendeling-Genootschap 1874 (Rotterdam: NZG, 1874), 39; Nederlandsch Zendeling-Genootschap, Maanberigten Voorgelezen Op de Maandelijksche Bedestonden van Het Nederlansch Zendeling-Genootschap 1889 (Rotterdam: NZG, 1889), 63, 84-87.

${ }^{21}$ De Hoofd-Kommissie van Onderwijs, Algemeen Verslag van Den Staat van Het Schoolwezen in Nederlansch-Indie 1857 (Batavia: Ter Lands Drukkerij, 1858), 112.

${ }^{22}$ Zendeling-Genootschap, Maanberigten Voorgelezen Op de Maandelijksche Bedestonden van Het Nederlansch Zendeling-Genootschap 1837, 184-85.

23 Nederlandsch Zendeling-Genootschap, Maanberigten Voorgelezen Op de Maandelijksche Bedestonden van Het Nederlansch Zendeling-Genootschap 1831 (Rotterdam: NZG, 1831), 107-11.

${ }^{24}$ Jacob, "Gereja Protestan Di Timor Barat Pada Masa Nederlandsch Zendeling Genootschap, 1820 1860: Suatu Kajian Mengenai Sejarah Dan Bentuknya," 33-35.

25 Zendeling-Genootschap, Maanberigten Voorgelezen Op de Maandelijksche Bedestonden van Het Nederlansch Zendeling-Genootschap 1837, 190; De Hoofd-Kommissie van Onderwijs, Algemeen Verslag van Den Staat van Het Schoolwezen in Nederlansch-Indie 1855, 131.

${ }^{26}$ I. J. Brugmans, Geschiedenis van Het Onderwijs in Nederlandsch-Indie (Batavia: Bij J. B. Wolters Uitgevers-Maatschappij, 1938), 115; Zendeling-Genootschap, Maanberigten Voorgelezen Op de Maandelijksche Bedestonden van Het Nederlansch Zendeling-Genootschap 1837, 190; Onderwijs, Algemeen Verslag van Den Staat van Het Schoolwezen in Nederlansch-Indie 1856, 131.

${ }^{27}$ Onderwijs, 133.

28 Nederlandsch Zendeling-Genootschap, Maanberigten Voorgelezen Op de Maandelijksche Bedestonden van Het Nederlansch Zendeling-Genootschap 1875 (Rotterdam: NZG, 1875), 144; Zendeling-Genootschap, Maanberigten Voorgelezen Op de Maandelijksche Bedestonden van Het Nederlansch Zendeling-Genootschap 1877, 87 \& 167.

${ }^{29}$ Kutipan ini telah diterjemahkan ke dalam bahasa Indonesia oleh penulis. Zendeling-Genootschap, Maanberigten Voorgelezen Op de Maandelijksche Bedestonden van Het Nederlansch ZendelingGenootschap 1876, 5.

${ }^{30}$ Kutipan ini telah diterjemahkan ke dalam bahasa Indonesia oleh penulis. Zendeling-Genootschap, Maanberigten Voorgelezen Op de Maandelijksche Bedestonden van Het Nederlansch ZendelingGenootschap 1837, 191.

${ }^{31}$ Zendeling-Genootschap, Maanberigten Voorgelezen Op de Maandelijksche Bedestonden van Het Nederlansch Zendeling-Genootschap 1831, 111.

32 Zendeling-Genootschap, Maanberigten Voorgelezen Op de Maandelijksche Bedestonden van Het Nederlansch Zendeling-Genootschap 1875, 161-62; Nederlandsch Zendeling-Genootschap, 
Maanberigten Voorgelezen Op de Maandelijksche Bedestonden van Het Nederlansch ZendelingGenootschap 1849 (Rotterdam: NZG, 1849), 77.

33 Nederlandsch Zendeling-Genootschap, Maanberigten Voorgelezen $O p$ de Maandelijksche Bedestonden van Het Nederlansch Zendeling-Genootschap 1841 (Rotterdam: NZG, 1841), 196-97; Nederlandsch Zendeling-Genootschap, Maanberigten Voorgelezen Op de Maandelijksche Bedestonden van Het Nederlansch Zendeling-Genootschap 1845 (Rotterdam: NZG, 1845), 111-12.

${ }^{34}$ Zendeling-Genootschap, 55.

35 Zendeling-Genootschap, Maanberigten Voorgelezen Op de Maandelijksche Bedestonden van Het Nederlansch Zendeling-Genootschap 1877, 39; Zendeling-Genootschap, Maanberigten Voorgelezen Op de Maandelijksche Bedestonden van Het Nederlansch Zendeling-Genootschap 1876, 158-59.

${ }^{36}$ Johannes L. Ch. Abineno, "Liturgische Vormen En Patronen in de Evangelische Kerk Op Timor", Ph.D Dissertation (Universeit Utrecht, 1956), 60-63.

37 Zendeling-Genootschap, Maanberigten Voorgelezen Op de Maandelijksche Bedestonden van Het Nederlansch Zendeling-Genootschap 1837, 186.

\section{DAFTAR PUSTAKA}

Abineno, Johannes L. Ch. "Liturgische Vormen En Patronen in de Evangelische Kerk Op Timor.” Universeit Utrecht, 1956.

Brugmans, I. J. Geschiedenis van Het Onderwijs in Nederlandsch-Indie. Batavia: Bij J. B. Wolters Uitgevers-Maatschappij, 1938.

Hoofd-Kommissie van Onderwijs, De. Algemeen Verslag van Den Staat van Het Schoolwezen in Nederlansch-Indie 1855. Batavia: Ter Lands Drukkerij, 1856.

Jacob, Fransico de Ch A. "Gereja Protestan Di Timor Barat Pada Masa Nederlandsch Zendeling Genootschap, 1820-1860: Suatu Kajian Mengenai Sejarah Dan Bentuknya." Theologia in Loco 3, no. 1 (2021): 19-42.

Onderwijs, De Hoofd-Kommissie van. Algemeen Verslag van Den Staat van Het Schoolwezen in Nederlansch-Indie 1832. Batavia: Ter Lands Drukkerij, 1833.

- Algemeen Verslag van Den Staat van Het Schoolwezen in Nederlansch-Indie 1852. Batavia: Ter Lands Drukkerij, 1853.

- Algemeen Verslag van Den Staat van Het Schoolwezen in Nederlansch-Indie 1856. Batavia: Ter Lands Drukkerij, 1857.

. Algemeen Verslag van Den Staat van Het Schoolwezen in Nederlansch-Indie 
1857. Batavia: Ter Lands Drukkerij, 1858.

Veth, P. J. Het Eiland Timor. Amsterdam: Penerbit tidak teridentifikasi, 1855.

Wellem, Frederiek Djara. Sejarah Gereja Masehi Injili Di Timor. Jakarta: Pertama Aksara, 2011.

Zendeling-Genootschap, Nederlandsch. Maanberigten Voorgelezen $O p$ de Maandelijksche Bedestonden van Het Nederlansch Zendeling-Genootschap 1827. Rotterdam: NZG, 1827.

- Maanberigten Voorgelezen Op de Maandelijksche Bedestonden van Het Nederlansch Zendeling-Genootschap 1831. Rotterdam: NZG, 1831.

- Maanberigten Voorgelezen Op de Maandelijksche Bedestonden van Het Nederlansch Zendeling-Genootschap 1836. Rotterdam: NZG, 1836.

- Maanberigten Voorgelezen Op de Maandelijksche Bedestonden van Het Nederlansch Zendeling-Genootschap 1837. Rotterdam: NZG, 1837.

- Maanberigten Voorgelezen Op de Maandelijksche Bedestonden van Het Nederlansch Zendeling-Genootschap 1839. Rotterdam: NZG, 1839.

- Maanberigten Voorgelezen Op de Maandelijksche Bedestonden van Het Nederlansch Zendeling-Genootschap 1841. Rotterdam: NZG, 1841.

- Maanberigten Voorgelezen Op de Maandelijksche Bedestonden van Het Nederlansch Zendeling-Genootschap 1842. Rotterdam: NZG, 1842.

- Maanberigten Voorgelezen Op de Maandelijksche Bedestonden van Het Nederlansch Zendeling-Genootschap 1843. Rotterdam: NZG, 1843.

- Maanberigten Voorgelezen Op de Maandelijksche Bedestonden van Het Nederlansch Zendeling-Genootschap 1845. Rotterdam: NZG, 1845.

- Maanberigten Voorgelezen Op de Maandelijksche Bedestonden van Het Nederlansch Zendeling-Genootschap 1849. Rotterdam: NZG, 1849.

- Maanberigten Voorgelezen Op de Maandelijksche Bedestonden van Het Nederlansch Zendeling-Genootschap 1874. Rotterdam: NZG, 1874.

- Maanberigten Voorgelezen Op de Maandelijksche Bedestonden van Het Nederlansch Zendeling-Genootschap 1875. Rotterdam: NZG, 1875.

- Maanberigten Voorgelezen Op de Maandelijksche Bedestonden van Het Nederlansch Zendeling-Genootschap 1876. Rotterdam: NZG, 1876. 
Pendidikan Kristen Di Keresidenan Timor Pada Masa Nederlandsch Zendeling Genootschap: Suatu Kajian Historis

. Maanberigten Voorgelezen Op de Maandelijksche Bedestonden van Het Nederlansch Zendeling-Genootschap 1877. Rotterdam: NZG, 1877.

- Maanberigten Voorgelezen Op de Maandelijksche Bedestonden van Het Nederlansch Zendeling-Genootschap 1889. Rotterdam: NZG, 1889.

- Maanberigten Voorgelezen Op de Maandelijksche Bedestonden van Het Nederlansch Zendeling-Genootschap 1890. Rotterdam: NZG, 1890.

- Maanberigten Voorgelezen Op de Maandelijksche Bedestonden van Het Nederlansch Zendeling-Genootschap 1891. Rotterdam: NZG, 1891.

- Maanberigten Voorgelezen Op de Maandelijksche Bedestonden van Het Nederlansch Zendeling-Genootschap 1892. Rotterdam: NZG, 1892. 